\title{
Dossiê: Políticas para a educação e a diversidade sociocultural: avanços, limites e desafios no enfrentamento das desigualdades
}

\author{
Joedson Brito dos Santos ${ }^{1}$, Juciley Evangelista Freire ${ }^{2}$, Adir Valdemar Garcia ${ }^{3}$ \\ ${ }_{1,2}$ Universidade Federal do Tocantins - UFT. Colegiado do curso de Pedagogia. Avenida Nossa Senhora de Fátima, 1588, Céu \\ Azul. Tocantinópolis-TO. Brasil. ${ }^{3}$ Universidade Federal de Santa Catarina - UFSC. \\ Autor para correspondência/Author for correspondence: jbsantus@uft.edu.br
}

A Revista Brasileira de Educação do Campo - RBEC, ISSN 2525-4863 -, periódico do Curso de Educação do Campo, da Universidade Federal do Tocantins (UFT), campus de Tocantinópolis, lança seu segundo número do volume 4, referente ao segundo trimestre de 2019. Este número apresenta 11 artigos aprovados dentre os manuscritos que foram recebidos entre o final de 2018 e início de 2019, de acordo com chamada pública para este dossiê.

A proposta do dossiê nasceu no contexto das atividades do "Núcleo de Estudos e Pesquisa em Educação, Desigualdade Social e Políticas Públicas” (Neped), da UFT, que vem desenvolvendo, desde 2015, no Tocantins, formação, estudos, pesquisa, debates e publicações que colocam em tela a relação Educação, Pobreza e Desigualdade Social (EPDS). Um das ações do núcleo se refere à organização e desenvolvimento de cursos como: o "Curso de Especialização Educação, Pobreza e Desigualdade Social”, que contribuiu com a formação e qualificação de mais de 300 profissionais que atuam na educação e/ou em contextos empobrecidos; e o "Curso de Aperfeiçoamento Educação, Pobreza e Desigualdade Social", em fase de finalização e que formará cerca de 200 estudantes de graduação, profissionais da educação, ativistas de movimentos sociais, bem como profissionais de outras áreas afins. Citamos, também, nesse contexto, a pesquisa intitulada “As políticas educacionais no contexto das desigualdades sociais e da situação de pobreza e extrema pobreza no estado do Tocantins", desenvolvida nos anos de 2016-2018; e a pesquisa "Trajetórias Escolares de estudantes em situação de pobreza na educação pública do Tocantins", ainda em andamento.

\begin{tabular}{|l|l|l|l|l|l|l|} 
RBEC & Tocantinópolis/Brasil & v. 4 & e6941 & $10.20873 /$ uft.rbec.v4e6941 & 2019 & ISSN: 2525-4863 \\
\hline
\end{tabular}


Outro importante trabalho foi a produção do vídeo-documentário "Educação e Pobreza no Tocantins" em 2017, que retrata a situação e a percepção de famílias beneficiárias do Programa Bolsa Família (PBF) e de profissionais que atuam nas escolas e na assistência social, no que concerne à importância desse programa para a educação das crianças em situação de pobreza.

Todas essas atividades estão vinculadas à Iniciativa Educação, Pobreza e Desigualdade Social (IEPDS), a partir da execução do Programa Nacional Educação, Pobreza e Desigualdade Social (PNEPDS), desenvolvido pela Secretaria de Educação Continuada, Alfabetização, Diversidade e Inclusão (SECADI), do Ministério da Educação (MEC). A IEPDS foi formulada em 2014, antes do golpe parlamentar, midiático e judiciário sofrido pelo governo Dilma Rousseff, em 2016, e tem, dentre seus objetivos, promover formação, reflexões, pesquisa e difusão de conhecimento sobre a relação “educação, pobreza e desigualdade social" e os sujeitos em situações de pobreza e de extrema pobreza.

As atividades desenvolvidas implicaram em maior interesse pela temática, levando à necessidade de, cada vez mais, compreender quem são e onde estão os sujeitos em condições de pobreza e extrema pobreza no Tocantins, na Região Norte e no Brasil. Além disso, buscouse entender, sobretudo, como os contextos escolares percebem, pensam e tratam esses sujeitos.

Os desafios para pautar o debate sobre a relação "educação, pobreza e desigualdades sociais" tendem a se ampliar. As proposições do governo Bolsonaro vão na contramão do processo que desencadeou esse debate. Dessa forma, a apreensão dos avanços, dos limites e dos desafios para a educação e para as políticas públicas acerca do acirramento das diversas formas de desigualdade, da negação dos direitos e das ameaças cada vez mais fortes à ordem democrática, requer reflexões e discussões no âmbito da academia, dos movimentos sociais e da sociedade política e civil.

A proposição para a reflexão do tema Políticas para a educação e a diversidade sociocultural: avanços, limites e desafios no enfrentamento das desigualdades tem uma significação importante à medida que busca dar visibilidade a questões que não dizem respeito apenas à realidade do campo, mas que, nesse espaço, tendem a ganhar contornos acentuados, visto que, em especial, a desigualdade de renda, que tem a pobreza como um dos seus polos, favorece a manutenção e a reprodução de outras desigualdades e a invisibilidade da diversidade sociocultural. A política de educação tem uma grande importância no que tange à redução dessas disparidades, mesmo que tenhamos clareza dos seus limites dentro da 
ordem do capital. Assim, os artigos que compõem este dossiê e que passamos a apresentar a seguir representam o esforço para compreender aspectos importantes da realidade da educação brasileira, sobretudo, da Educação do Campo e expressam as diversas desigualdades que permeiam a sociedade brasileira e afetam as crianças em idade escolar, em especial, aquelas da realidade campesina.

No primeiro artigo, intitulado Alfabetização do campo no âmbito do PNAIC: propostas e dilemas, Sidmar da Silva Oliveira, Obdália Santana Ferraz Silva e Úrsula Cunha Anecleto, da Universidade do Estado da Bahia (UNEB), discutem possíveis implicações do Pacto Nacional Pela Alfabetização na Idade Certa (PNAIC) para a alfabetização do campo. Embasado na análise textual-discursiva e em uma pesquisa documental, o estudo aponta que a formação continuada apresenta maior relevância quando tem, como elemento constitutivo, a reflexão colaborativa dos professores envolvidos com a prática alfabetizadora no cotidiano escolar, particularmente, no que se refere às escolas do campo. A investigação conclui, ainda, que o PNAIC para o campo precisa estabelecer uma relação mais próxima com as escolas desse espaço para captar suas reais demandas educacionais.

O segundo artigo, $\mathbf{O}$ ensino em turmas multisseriadas e suas condições de trabalho: um olhar para as escolas do campo na região do Alto Solimões, Amazonas, de autoria de Jarliane da Silva Ferreira, da Universidade Federal do Amazonas (UFAM), discute sobre a educação do campo na região do Alto Solimões, Amazonas, considerando o ensino em turmas multisseriadas e as condições objetivas de professores e alunos. O estudo mostrou que muitas das turmas analisadas parecem evidenciar o fracasso e a precariedade escolar. A investigação mostrou também que a existência de muitas turmas multisseriadas na região se apresenta como a única alternativa de acesso à educação escolar em localidades distantes e que professores e alunos do campo demandam melhores condições de infraestrutura escolar, valorização docente e transporte.

$\mathrm{Na}$ sequência, temos o artigo Escolarização, profissionalização e desenvolvimento em escola do campo, de José Bittencourt da Silva, da Universidade Federal do Pará (UFPa), que analisa o desenvolvimento socioeconômico e educacional de egressos escolarizados na Casa Escola da Pesca (CEPE): uma escola municipal do campo de regime integral e que atende na modalidade EJA, com habilitação profissional técnica na área da pesca. A pesquisa concluiu que as condições materiais objetivas dos sujeitos correlacionadas à ausência de relações cotidianas em contextos organizativos condicionam, negativamente, o desenvolvimento socioeconômico e educacional dos egressos da CEPE. 
O quarto artigo, intitulado Reflexões sobre os egressos do curso de Licenciatura em Educação do Campo da Universidade de Brasília: os elementos para "Transformar (ação) Pedagógica" na Educação Superior, das autoras Márcia Mariana Bittencourt Brito e Mônica Castagna Molina, da Universidade de Brasília (UnB), traz uma análise da atuação dos(as) egressos(as) do curso de Licenciatura em Educação do Campo da Universidade de Brasília. No estudo, as autoras adotaram o Materialismo Histórico-dialético como epistemologia e método. Elas apresentam alguns dos elementos de transforma(ação) pedagógica que o curso de Licenciatura em Educação do Campo provocou nos últimos 10 (dez) anos na Educação Superior.

O artigo seguinte intitulado Reflexões em busca do cuidado com o currículo escolar das escolas localizadas no campo do Município de Humaitá (AM), de autoria de Zilda Gláucia Elias Franco, da Universidade Federal do Amazonas (UFAM), trata sobre a dimensão do cuidado na justiça curricular, compreendida como função exercida pelo currículo escolar, no sentido de que as escolas atendam às necessidades dos envolvidos, formando sujeitos corresponsáveis pela construção de uma sociedade mais justa. A autora observa que as escolas localizadas na área rural de Humaitá, no Amazonas, necessitam de um debate sobre currículo escolar, considerando a concepção da justiça curricular, em especial, a dimensão do cuidado.

Elizabeth Moreira Gomes, Alexandre Fraga de Araújo e Maria Isabel Antunes-Rocha, da Universidade Federal de Minas Gerais (UFMG), no artigo Legislação sobre posse de terras e Educação do Campo no Brasil, refletem acerca de duas questões que envolvem os campesinos: a questão da terra e a educação do campo. Os autores evidenciam as relações entre a construção da "invisibilidade" das populações campesinas e a constituição de um movimento em prol de uma educação que considere suas especificidades, bem como que as lutas em defesa de uma educação de qualidade para os sujeitos campesinos vêm alcançando conquistas de modo a torná-los visíveis.

Em Violência, luta e resistência: da educação rural à educação escolar indígena, Leni Barbosa Feitosa e Idemar Vizolli, da Universidade Federal do Tocantins (UFT), têm por objetivo deslindar, por meio da historicidade, como a perspectiva da educação rural se tornou educação escolar indígena, legitimando e valorizando, no ambiente educacional, seus modos próprios de pensar, produzir e expressar conhecimentos que emanam de suas culturas. O texto destaca que o advento da educação escolar indígena não é resultado do "bem querer" do Estado, mas da luta e resistência desses povos a inúmeras imposições. 
O artigo intitulado Da teimosa resistência nasce a Escola Estadual do Campo Madre Cristina, de Sandra Maria Soares e Ronaldo Eustáquio Feitoza Senra, do Instituto Federal do Mato Grosso (IFMT), apresenta as lutas e os enfrentamentos vivenciados pelos (as) educadores (as) para a continuidade da Escola Estadual Madre Cristina-EEMC. O estudo, resultado de uma pesquisa participante, evidenciou que os (as) educadores (as) da escola têm conseguido permanecer no campo com o apoio dos(as) assentados(as), dando continuidade ao espaço escolar. No entanto, esses atires vivenciam muitos desafios na luta pela permanência da escola.

José Douglas Alves dos Santos e Éverton Vasconcelos de Almeida, da Universidade Federal de Santa Catarina (UFSC), no artigo Chico Bento e as representações sociais da infância, realizam uma reflexão sobre o imaginário de crianças e infâncias rurais, utilizando um dos principais símbolos de representação da criança camponesa brasileira: o personagem de Chico Bento. Os autores constataram que essa produção visual (re)produz discursos sobre o campo e seus sujeitos, permeados por estereótipos e preconceitos, e que essa produção cultural imagética tem grande relevância na construção do olhar e da leitura social que a ela se direciona.

\section{$\mathrm{O}$ artigo Pressupostos do paradigma do Capital Humano aplicados à Primeira}

Infância, de autoria de Joedson Brito dos Santos, da Universidade Federal do Tocantins (UFT), resultado de uma pesquisa qualitativa de cunho bibliográfico, traz uma discussão sobre o paradigma do capital humano aplicado à primeira infância. $\mathrm{O}$ estudo constatou que a atenção, a educação e o desenvolvimento da criança têm sido considerados a solução para os problemas sociais e para o desenvolvimento econômico sustentável pois, pressupõe-se que esses elementos geram retornos econômicos e eliminam as desigualdades. Contudo, as orientações e programas direcionados para a primeira infância dos países em desenvolvimento, são de natureza assistencialista e compensatória, com foco no alívio à pobreza.

O último artigo desse dossiê, intitulado Desigualdade racial e fracasso escolar de estudantes negras e negros, de Ladislau Ribeiro do Nascimento, da Universidade Federal do Tocantins (UFT), baseado em referências produzidas na interface da Psicologia com a Educação, propõe uma reflexão sobre a desigualdade racial como fenômeno atrelado ao fracasso escolar. O texto aborda o tema como um fenômeno complexo, produzido e reproduzido a partir da influência de forças engendradas nos campos político, econômico, institucional e social. O autor busca evidenciar conexões entre a desigualdade racial e social e 
a produção do fracasso escolar, como também analisa a correlação entre: estigma, invisibilidade e silenciamento de estudantes negras e negros.

Agradecemos a todos que submeteram seus manuscritos, a cada um dos(as) autores(as) desse dossiê e a todos(as) os(as) avaliadores(as) ad hoc que contribuíram com a apreciação, leitura atenta e análise dos textos. Agradecemos, de modo particular, aos editores da "Revista Brasileira da Educação do Campo", tanto pelo trabalho e atenção quanto pela oportunidade de colocar para o debate o tema e as questões em tela.

Desejamos uma boa leitura, reflexão e compartilhamento dos textos a seguir.

\section{Joedson Brito dos Santos, Juciley Evangelista Freire e Adir Valdemar Garcia.}

Informações do Editorial / Editorial Information

Conflitos de interesse: Os autores declararam não haver nenhum conflito de interesse referente a este Editorial.

Conflict of Interest: None reported.

\section{Orcid}

Joedson Brito dos Santos

(iD) http://orcid.org/0000-0003-4394-9294

Juciley Evangelista Freire

(iD)

http://orcid.org/0000-0001-9613-8108

Adir Valdemar Garcia

(iD)

http://orcid.org/0000-0001-7805-4242

Como citar este artigo / How to cite this article

APA

Santos, J. B., Freire, J. E., \& Garcia, A. V. (2019). Dossiê: Políticas para a educação e a diversidade sociocultural: avanços, limites e desafios no enfrentamento das desigualdades. Rev. Bras. Educ. Camp., 4, e6941. DOI: http://dx.doi.org/10.20873/uft.rbec.e6941

ABNT

SANTOS, J. B.; FREIRE, J. E.; GARCIA, A. V. Dossiê: Políticas para a educação e a diversidade sociocultural: avanços, limites e desafios no enfrentamento das desigualdades. Rev. Bras. Educ. Camp., Tocantinópolis, v. 4, e6941, 2019. DOI: http://dx.doi.org/10.20873/uft.rbec.e6941 